\title{
Berberine prevents nigrostriatal dopaminergic neuronal loss and suppresses hippocampal apoptosis in mice with Parkinson's disease
}

\author{
MIA KIM ${ }^{1}$, KI-HO CHO ${ }^{1}$, MAL-SOON SHIN ${ }^{2}$, JAE-MIN LEE ${ }^{2}$, HAN-SAM CHO ${ }^{2}$, \\ CHANG-JU KIM ${ }^{2}$, DONG-HOON SHIN ${ }^{3}$ and HYEON JEONG YANG ${ }^{4}$ \\ ${ }^{1}$ Department of Cardiovascular and Neurologic Diseases (Stroke Center), \\ College of Oriental Medicine, ${ }^{2}$ Department of Physiology, College of Medicine, Kyung Hee University, \\ Seoul 130-701; ${ }^{3}$ Department of Food and Biotechnology, Graduate School of Life Sciences and Biotechnology, \\ Korea University, Seoul 136-701, ${ }^{4}$ Department of Anesthesiology and Pain Medicine, \\ CHA Bundang Medical Center, CHA University, Seongnam 463-721, Republic of Korea
}

Received August 21, 2013; Accepted December 10, 2013

DOI: $10.3892 / \mathrm{ijmm} .2014 .1656$

\begin{abstract}
Parkinson's disease (PD) is a progressive neurodegenerative disorder characterized by the selective loss of nigral dopaminergic neurons and a reduction in striatal dopaminergic fibers, which result in tremors, rigidity, bradykinesia and gait disturbance. In addition to motor dysfunction, dementia is a widely recognized symptom of patients with PD. Berberine, an isoquinoline alkaloid isolated from Berberis vulgaris L., is known to exert anxiolytic, analgesic, anti-inflammatory, antipsychotic, antidepressant and anti-amnesic effects. In the present study, we investigated the effects of berberine on short-term memory in relation to dopamine depletion and hippocampal neurogenesis using a mouse model of PD, induced by 1-methyl-4-phenyl-1,2,3,6-tetrahydropyridine/probenecid (MPTP/P) treatment. Mice in the berberine-treated groups were orally administered berberine once a day for a total of 5 weeks. Our results revealed that the injection of MPTP/P induced dopaminergic neuronal death in the substantia nigra and fiber loss in the striatum. This resulted in impaired motor balance and coordination, as assessed by the beam walking test. We further demonstrated that MPTP/P-induced apoptosis in the hippocampus deteriorated short-term memory, as shown by the step-down avoidance task. By contrast, neurogenesis in the hippocampal dentate gyrus, which is a compensatory adaptive response to excessive apoptosis, was increased upon PD induction. However, treatment with berberine enhanced motor balance and coordination by preventing dopaminergic neuronal
\end{abstract}

Correspondence to: Professor Hyeon Jeong Yang, Department of Anesthesiology and Pain Medicine, CHA Bundang Medical Center, CHA University, 59 Yatap-ro, Bundang-gu, Seongnam, Gyeonggi 463-721, Republic of Korea

E-mail: ganglions@hanmail.net

Key words: Parkinson's disease, berberine, tyrosine hydroxylase, neurogenesis, apoptosis damage. Treatment with berberine also improved short-term memory by inhibiting apoptosis in the hippocampus. Berberine demonstrated maximal potency at $50 \mathrm{mg} / \mathrm{kg}$. Based on these data, treatment with berberine may serve as a potential therapeutic strategy for the alleviation of memory impairment and motor dysfunction in patients with PD.

\section{Introduction}

Parkinson's disease (PD) is a progressive neurodegenerative disorder characterized by the selective loss of nigral dopaminergic neurons and a reduction in striatal dopaminergic fibers, which result in tremors, rigidity, bradykinesia and gait disturbance (1). In addition to motor dysfunction, dementia is a widely recognized symptom of patients with PD. Degeneration of the dopaminergic neurons during PD may affect the hippocampal dentate gyrus (2).

Tyrosine hydroxylase (TH) is the rate-limiting enzyme in the biosynthetic pathways of catecholamine-type neurotransmitters, such as dopamine, epinephrine and norepinephrine. More specifically, this enzyme converts L-tyrosine into L-dihydroxyphenylalanine (L-DOPA), and this is the rate-limiting step in the synthesis of dopamine (3). Since TH is an enzyme of the dopamine biosynthetic pathway, TH activity progressively decreases following the loss of dopaminergic neurons within the substantia nigra $(4,5)$.

Cell proliferation and/or neurogenesis have been demonstrated to occur in the hippocampal dentate gyrus in the brain of adult mammals, including humans $(6,7)$. The generation of new neurons in the hippocampus plays an important role in hippocampal functions, such as learning and memory $(8,9)$. However, brain diseases, such as cerebral ischemia, trauma and epileptic seizures, are accompanied by increased neurogenesis (10-12). The induction of hippocampal neurogenesis in pathological conditions is considered a compensatory response to dopaminergic neuronal death (2).

Apoptosis plays a critical role in neuronal cell death, occuring in a number of neurodegenerative diseases, including PD, Alzheimer's disease and epilepsy, as well as in stroke $(4,13,14)$. 
Two important groups of proteins involved in apoptotic cell death are the members of the Bcl-2 family, Bax and Bcl-2, and a class of cysteine proteases known as caspases $(15,16)$. The Bcl-2 family comprises two functionally distinct groups of proteins: the anti-apoptotic and the pro-apoptotic proteins. Bcl-2, an anti-apoptotic protein, protects against cell death, whereas Bax, a pro-apoptotic protein, promotes cell death. Increasing the ratio of Bax to Bcl-2 has commonly been used to determine the induction of apoptosis in a number of tissues (16). Caspase-3 is one of the key enzymes in cell apoptosis, since it can cleave a number of proteins (15). Caspase-3 is the primary activator of DNA fragmentation (17); the latter is experimentally detected by the terminal deoxynucleotidyl transferase-mediated dUTP nick end-labeling (TUNEL) assay.

Berberine, an isoquinoline alkaloid isolated from Berberis vulgaris L., is known to exhibit anxiolytic, analgesic, antiinflammatory, antipsychotic, antidepressant and anti-amnesic properties $(18,19)$. Berberine has been shown to improve spatial memory impairment in a rat model of Alzheimer's disease and memory impairment in a rat model of diabetes $(20,21)$. The fact that berberine exerts anti-inflammatory effects suggests that it may have an inhibitory effect on the degeneration of cholinergic neurons (22).

The effects of berberine on a number of brain diseases have been well documented $(20,21,23)$; however, studies on the effects of berberine on PD have reported controversial results (24,25). Bae et al (24) suggested that berberine may be useful as a therapeutic agent in the treatment of neurological disorders. However, Kwon et al (25) reported that treatment with berberine reduced the number of $\mathrm{TH}$-immunopositive cells in the substantia nigra of rats and enhanced 6-hydroxydopamine (6-OHDA)-induced cytotoxicity in PC12 cells. To our knowledge, to date, the effects of beberine on memory function in relation to neurogenesis and apoptosis have not been investigated in mice with PD. Thus, in the present study, we investigated the effects of berberine on short-term memory in relation to dopamine depletion and hippocampal neurogenesis using a mouse model of PD, induced by 1-methyl4-phenyl-1,2,3,6-tetrahydropyridine/probenecid (MPTP/P) treatment.

\section{Materials and methods}

Animals. Imprinting control region (ICR) male mice weighing $28 \pm 3 \mathrm{~g}$ ( 8 weeks old) were used in this study. They were kept in controlled temperature $\left(20 \pm 2^{\circ} \mathrm{C}\right)$ conditions under a 12-h light/12-h dark cycle. The animals were allowed free access to food and water. All experimental animal procedures conformed with the relevant regulations of the National Institutes of Health (NIH) and the guidelines of the Korean Academy of Medical Sciences. The animals were randomly divided into 5 groups ( $\mathrm{n}=10$ in each group): the control group (probenecid-injected), the MPTP/P-injected group, the MPTP/P-injected and $20 \mathrm{mg} / \mathrm{kg}$ berberine-treated group, the MPTP/P-injected and $50 \mathrm{mg} / \mathrm{kg}$ berberine-treated group, and the MPTP/P-injected and $80 \mathrm{mg} / \mathrm{kg}$ berberine-treated group. All mice were intraperitoneally administered $50 \mathrm{mg} / \mathrm{kg} 5$-bromo2'-deoxyuridine (BrdU; Sigma Chemical Co., St. Louis, MO, USA) once a day 30 min prior to berberine treatment, for 4 consecutive days. Mice in the berberine-treated groups were orally administered berberine (Sigma Chemical Co.) at the respective doses, once a day for 5 weeks. Mice in the control group and the MPTP/P-injected group received the same amount of distilled water.

Mouse model of MPTP-induced PD. MPTP is a neurotoxin that selectively damages dopaminergic cells in the substantia nigra pars compacta (SNpc), and is widely used to induce PD in rodents and primates $(26,27)$. MPTP hydrochloride and probenecid (P) were purchased from Sigma Chemical Co. In order to establish the mouse model of MPTD-induced PD, the mice were injected with MPTP hydrochloride $[20 \mathrm{mg} / \mathrm{kg}$ in saline, subcutaneously (s.c.)] with probenecid as an adjuvant $[250 \mathrm{mg} / \mathrm{kg}$ in dimethylsulfoxide, intraperitoneally (i.p.)] 10 times for 5 weeks at 3.5-day intervals, as previously described $(4,28)$. The control mice were treated with the same volume of probenecid following the same procedure. Probenecid is known to promote the build-up of MPTP or its derivative, 1-methyl-4-phenylpyridinium $\left(\mathrm{MPP}^{+}\right)$in the brain and to potentiate its neurotoxic effects by impeding the renal excretion and neuronal clearance of MPTP and its toxic metabolites (28). Importantly, probenecid does not affect the degeneration of dopaminergic neurons (29).

Step-down avoidance task. The latency time in the step-down avoidance task was measured in order to evaluate short-term memory, as previously described (9). The mice were trained in a step-down avoidance task on the 34 days following the start of the experiment. Two hours after training, the latency time (sec) in each group was measured. The mice were placed on a $5 \times 25 \mathrm{~cm}$ platform of $1 \mathrm{~cm}$ in height facing a $42 \times 25 \mathrm{~cm}$ grid of parallel stainless steel bars, $0.1 \mathrm{~cm}$ in caliber, spaced $1 \mathrm{~cm}$ apart. In the training sessions, the animals received a $0.5 \mathrm{~mA}$ scramble foot shock for $2 \mathrm{sec}$ immediately upon stepping down. The interval of time which elapsed between the mice stepping down and placing all 4 paws on the grid was defined as the latency time. A latency time $>180 \mathrm{sec}$ was registered as $180 \mathrm{sec}$.

Beam walking test. The beam walking test is a motor skill and balance test and was conducted according to a previously described method (30). The apparatus consisted of an acrylic round beam ( $60 \mathrm{~cm}$ long, $1.5 \mathrm{~cm}$ wide) and 2 vertical supports (60 cm high) above a round tank (150 cm in diameter). Each mouse was given 3 successive trials and perpendicularly placed on the center of the beam. Each trial was recorded for a maximum of $60 \mathrm{sec}$.

Tissue preparation. Following the completion of the behavioral tests, the mice were deeply anesthetized by an injection of Zoletil $50^{\circledR}(1 \mathrm{mg} / \mathrm{kg}$, i.p.; Virbac Laboratories, Carros, France). The mice were then transcardially perfused with $0.05 \mathrm{M}$ phosphate-buffered saline (PBS), followed by $4 \%$ paraformaldehyde in $0.5 \mathrm{M}$ sodium phosphate buffer at $\mathrm{pH}$ 7.4. The brains were removed, post-fixed in the same fixative solution overnight, and transferred to a $30 \%$ sucrose solution for cryoprotection. Serial $30-\mu \mathrm{m}$-thick coronal sections were made using a freezing microtome (Leica Biosystems Nussloch $\mathrm{GmbH}$, Nussloch, Germany). Brain tissues were selected from each brain in the region spanning -2.92 to $-3.64 \mathrm{~mm}$ from the 
bregma for the SNpc and from the region spanning 0.74 to $0.26 \mathrm{~mm}$ from the bregma for the striatum.

Immunohistochemistry for cleaved caspase-3. For the visualization of cleaved caspase-3, immunohistochemistry was performed, according to a previously described method (9). Briefly, the sections were incubated overnight with a rabbit anti-cleaved caspase-3 antibody (1:500; Cell Signaling Technology, Beverly, MA, USA) and were incubated for an additional hour with the biotinylated rabbit secondary antibody. The bound secondary antibody was then amplified using the Elite ABC kit ${ }^{\circledR}$ (Vector Laboratories Inc., Burlingame, CA, USA). The antibody-biotin-avidin-peroxidase complex was visualized using $0.02 \%$ 3,3'-diaminobenzidine (DAB). The sections were mounted onto gelatin-coated slides that were air-dried overnight at room temperature, and the coverslips were mounted using Permount medium (Thermo Fisher Scientific Inc., Fair Lawn, NJ, USA).

TUNEL assay. To visualize DNA fragmentation, a TUNEL assay was performed using the In Situ Cell Death Detection kit ${ }^{\mathbb{}}$ (Roche Diagnostics GmbH, Mannheim, Germany), following the manufacturer's instructions. First, the sections were post-fixed in an ethanol-acetic acid (2:1) mixture and rinsed. Subsequently, the sections were incubated with $100 \mu \mathrm{g} / \mathrm{ml}$ proteinase $\mathrm{K}$, rinsed, incubated in $3 \% \mathrm{H}_{2} \mathrm{O}_{2}$, permeabilized with $0.5 \%$ Triton $\mathrm{X}-100$, rinsed again, and incubated in the TUNEL reaction mixture. The sections were rinsed, $0.02 \% \mathrm{DAB}$ was added and visualized using a Converter-POD. Mayer's hematoxylin dye (Dako, Glostrup, Denmark) was used for counterstaining, the sections were mounted onto gelatin-coated slides that were air-dried overnight at room temperature, and the coverslips were mounted using Permount medium (Thermo Fisher Scientific).

BrdU/NeuN immunofluorescence. Immunofluorescence staining was used to detect the number of BrdU-positive and neuronal nuclear antigen (NeuN)-positive cells in the hippocampal dentate gyrus following a previously described method (9). Briefly, the brain sections were permeabilized by incubation with $0.5 \%$ Triton X-100 in PBS for 20 min, then incubated with $50 \%$ formamide-2X standard saline citrate (SSC) at $65^{\circ} \mathrm{C}$ for $2 \mathrm{~h}$, denaturated in $2 \mathrm{~N} \mathrm{HCl}$ at $37^{\circ} \mathrm{C}$ for $30 \mathrm{~min}$, and rinsed twice in $100 \mathrm{mM}$ sodium borate $(\mathrm{pH} 8.5)$. The sections were incubated overnight with rat anti-BrdU antibody (1:500; Abcam, Cambridge, UK) and mouse anti-NeuN antibody (1:500; EMD Millipore Corp., Billerica, MA, USA). The sections were then incubated for $2 \mathrm{~h}$ with $\mathrm{Cy} 3$-conjugated anti-rat secondary antibody (1:200) for the BrdU assay and with fluorescein isothiocyanate (FITC)-conjugated antimouse (1:200) antibody (both from Jackson ImmunoResearch Laboratories Inc., West Grove, PA, USA) for the NeuN assay. The sections were then mounted on gelatin-coated glass slides, and the coverslips were mounted using fluorescent mounting medium (Dakocytomation, Carpinteria, CA, USA). Images were captured under a confocal laser scanning microscope (LSM-700; Carl Zeiss Microscopy GmbH, Oberkochen, Germany). On average, 6 sections were selected from each brain, from the dentate gyrus area spanning -1.34 to $-3.28 \mathrm{~mm}$ from the bregma. The number of BrdU/NeuN-labeled cells was counted under a confocal laser scanning microscope. The results were expressed as the number of BrdU/NeuN-labeled cells $/ \mathrm{mm}^{2}$.

TH immunohistochemistry. The expression level of TH in the $\mathrm{SNpc}$ and striatum was assessed by immunohistochemistry, following a previously described method (4). The sections were rinsed in PBS and incubated with $3 \% \mathrm{H}_{2} \mathrm{O}_{2}$ for $20 \mathrm{~min}$ to block the endogenous peroxidase activity. After washing with PBS, the sections were incubated with blocking serum (10\% horse serum and $0.1 \%$ Triton X-100 in PBS) for $30 \mathrm{~min}$, followed by incubation with an anti-TH mouse monoclonal antibody solution (1:1,000; BD Biosciences, Franklin Lakes, NJ, USA) for $24 \mathrm{~h}$ at room temperature. The sections were then incubated for $1 \mathrm{~h}$ with biotinylated anti-mouse IgG secondary antibody (1:300; Vector Laboratories Inc.). The sections were subsequently incubated with the avidin-biotin-peroxidase complex (Vector Laboratories Inc.) for $1 \mathrm{~h}$ at room temperature. Immunoreactivity was visualized by incubating the sections for 3 min with a solution consisting of $0.05 \% \mathrm{DAB}$ and $0.01 \% \mathrm{H}_{2} \mathrm{O}_{2}$ in $50 \mathrm{mM}$ Tris buffer ( $\mathrm{pH}$ 7.6). The sections were mounted on gelatine-coated slides and coverslipped using Permount mounting medium (Thermo Fisher Scientific). Cell counting and optical density measurements were performed using the computer-assisted Image-Pro ${ }^{\circledR}$ Plus (Media Cybernetics, Inc., Silver Spring, MD, USA) image analysis system, attached to a light microscope (Olympus, Tokyo, Japan).

Western blot analysis. In order to measure $\mathrm{Bax}$ and $\mathrm{Bcl}-2$ protein expression, western blot analysis was performed, following a previously described protocol (9). Hippocampal samples were dissected from the mice, and stored at $-70^{\circ} \mathrm{C}$ until further analysis. The samples were lysed by incubation, for $30 \mathrm{~min}$ at $4^{\circ} \mathrm{C}$, with ice-cold lysate buffer containing $50 \mathrm{mM}$ HEPES (pH 7.5), $150 \mathrm{mM} \mathrm{NaCl}, 10 \%$ glycerol, $1 \%$ Triton X-100, $1.5 \mathrm{mM}$ magnesium chloride hexahydrate, $1 \mathrm{mM}$ ethyleneglycol-bis-( $\beta$-aminoethyl ether)-N,N'-tetraacetic acid (EGTA), $1 \mathrm{mM}$ phenylmethylsulfonyl fluoride (PMSF), $2 \mu \mathrm{g} / \mathrm{ml}$ leupeptin, $1 \mu \mathrm{g} / \mathrm{ml}$ pepstatin, $1 \mathrm{mM}$ sodium orthovanadate and $100 \mathrm{mM}$ sodium fluoride. The tissue debris was then removed by microcentrifugation, while the supernatant was immediately frozen. Protein concentrations were measured using a colorimetric protein assay kit (BioRad, Hercules, CA, USA). Proteins (30 $\mu \mathrm{g})$ were separated on SDS-polyacrylamide gels and transferred onto a nitrocellulose membrane (Whatman Inc., Clifton, NJ, USA). Mouse anti-Bax $(1: 1,000)$ and anti-Bcl-2 $(1: 1,000)$ (both from Santa Cruz Biotechnology, Inc., Santa Cruz, CA, USA) were used as the primary antibodies. Horseradish peroxidase-conjugated anti-mouse (1:3,000; Vector Laboratories Inc.) were used as the secondary antibodies. Band detection was performed using the enhanced chemiluminescence (ECL) detection system (Stanta Cruz Biotechnology, Inc.). The bands were then quantified using the computer-assisted Image-Pro Plus analysis system.

Statistical analysis. All data were analyzed using SPSS 20.0 software (SPSS Inc., Chicago, IL, USA). The data are expressed as the means \pm standard error of the mean (SEM). For the comparison among groups, one-way ANOVA and Duncan's 

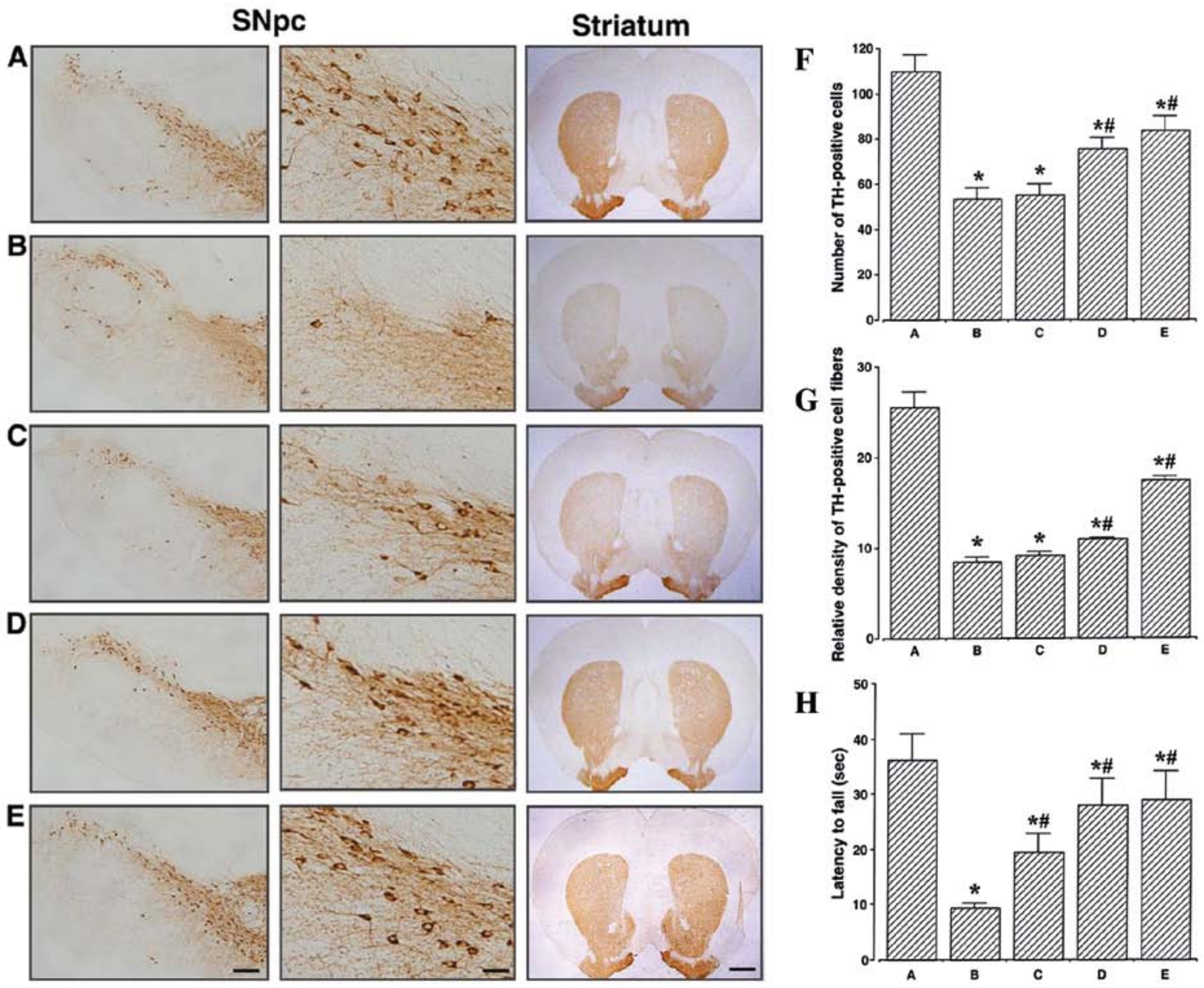

Figure 1. Effects of berberine on tyrosine hydroxylase (TH) expression in the substantia nigra pars compacta (SNpc) and the striatum. (A-E) Photomicrographs showing TH in the SNpc at low (left panel scale bar, $200 \mu \mathrm{m}$ ) and high magnification (middle panel scale bar, $50 \mu \mathrm{m}$ ) and in the striatum (right panel scale bar, $800 \mu \mathrm{m}$ ). (A) Control group, (B) 1-methyl-4-phenyl-1,2,3,6-tetrahydropyridine/probenecid (MPTP/P)-injected group, (C) MPTP/P-injected and 20 mg/ $\mathrm{kg}$ berberine-treated group, (D) MPTP/P-injected and $50 \mathrm{mg} / \mathrm{kg}$ berberine-treated group, and (E) MPTP/P-injected and $80 \mathrm{mg} / \mathrm{kg}$ berberine-treated group (F) Number of TH-positive cells in SNpc, (G) relative density of TH-positive fibers in the striatum, and (H) motor balance and coordination skills of mice from groups A-E. Measurements of latency time until fall are from the beam walking test. Data are presented as the means \pm standard error of the mean (SEM). ${ }^{\text {* }} \mathrm{P}<0.05$ compared to the control group; ${ }^{*} \mathrm{P}<0.05$ compared to the MPTP/P-injected group. P-values were obtained by Duncan's tests.

post-hoc tests were performed, with $\mathrm{P}<0.05$ as the threshold p-value for statistical significance.

\section{Results}

Effects of berberine on nigrostriatal dopaminergic neurons, motor balance and coordination. The photomicrographs of TH-positive cells in the SNpc and striatum which were obtained are presented in Fig. 1A-E. The number of the TH-immunoreactive neurons in the SNpc was $109.87 \pm 7.22 /$ section in the control group, 53.50 $\pm 4.88 /$ section in the MPTP/ P-injected group, 55.29 $\pm 4.57 /$ section in the MPTP/P-injected and $20 \mathrm{mg} / \mathrm{kg}$ berberine-treated group, $75.89 \pm 4.49 / \mathrm{section}$ in the MPTP/P-injected and $50 \mathrm{mg} / \mathrm{kg}$ berberine-treated group, and $83.75 \pm 6.49 /$ section in the MPTP/P-injected and $80 \mathrm{mg} / \mathrm{kg}$ berberine-treated group (Fig. 1F). These results demonstrated that berberine treatment alleviated the MPTP/P-induced neuronal cell loss in the SNpc $(\mathrm{P}<0.05)$.
The optical density of the TH-immunoreactive fibers in the striatum was $25.52 \pm 1.74$ in the control group, $8.46 \pm 0.54$ in the MPTP/P-injected group, 9.18 \pm 0.44 in the MPTP/P-injected and $20 \mathrm{mg} / \mathrm{kg}$ berberine-treated group, $10.99 \pm 0.15$ in the MPTP/P-injected and $50 \mathrm{mg} / \mathrm{kg}$ berberine-treated group, and $17.49 \pm 0.34$ in the MPTP/P-injected and $80 \mathrm{mg} / \mathrm{kg}$ berberine-treated group (Fig. 1G). These results indicated that berberine treatment alleviated the MPTP/P-induced dopaminergic fiber loss in the striatum $(\mathrm{P}<0.05)$.

The results of the beam walking test, performed to evaluate the motor balance and coordination of the mice in all the groups, are presented in Fig. 1H. The latency until fall in this test was found to be $36.20 \pm 4.67 \mathrm{sec}$ in the control group, $9.37 \pm 0.89 \mathrm{sec}$ in the MPTP/P-injected group, $19.40 \pm 3.44 \mathrm{sec}$ in the MPTP/P-injected and $20 \mathrm{mg} / \mathrm{kg}$ berberine-treated group, $28.00 \pm 4.81 \mathrm{sec}$ in the MPTP/P-injected and $50 \mathrm{mg} / \mathrm{kg}$ berberinetreated group, and $29.00 \pm 5.28 \mathrm{sec}$ in the MPTP/P-injected and $80 \mathrm{mg} / \mathrm{kg}$ berberine-treated group. These results demonstrated 

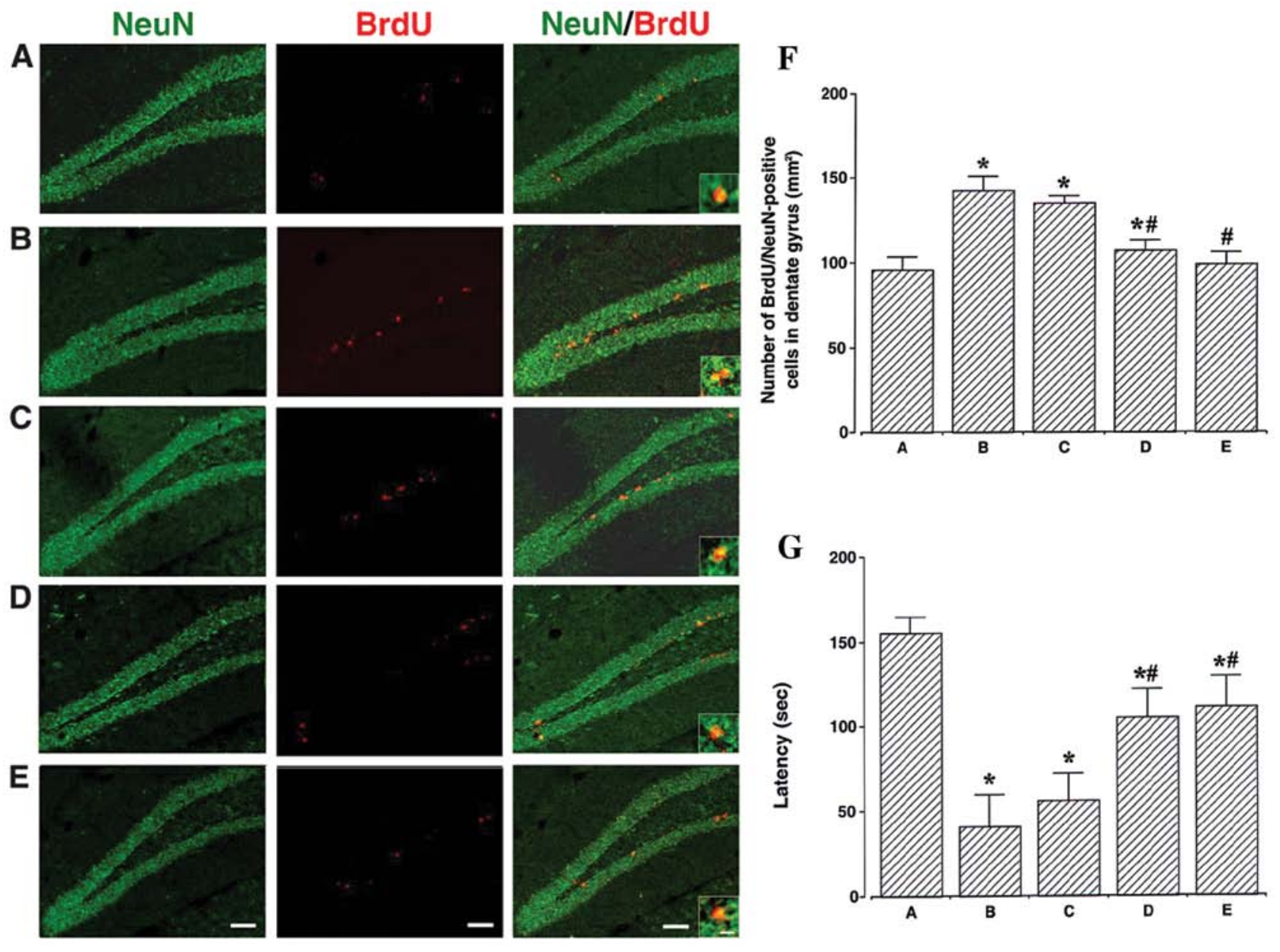

Figure 2. Effects of berberine on neurogenesis in the hippocampal dentate gyrus. (A-E) Photomicrographs showing immunofluorescence of neuronal nuclear antigen (NeuN, green), 5-bromo-2'-deoxyuridine (BrdU, red), or their superposition (NeuN/BrdU) at low (scale bar, $50 \mu \mathrm{m}$ ) and high magnification (scale bar, $10 \mu \mathrm{m}$, enclosed images). (A) Control group, (B) 1-methyl-4-phenyl-1,2,3,6-tetrahydropyridine/probenecid (MPTP/P)-injected group, (C) MPTP/P-injected and $20 \mathrm{mg} / \mathrm{kg}$ berberine-treated group, (D) MPTP/P-injected and $50 \mathrm{mg} / \mathrm{kg}$ berberine-treated group and (E) MPTP/P-injected and $80 \mathrm{mg} / \mathrm{kg}$ berberine-treated group. (F) Number of BrdU/NeuN-positive cells in the hippocampal dentate gyrus and (G) latency (from step-down avoidance task) of mice from groups A-E. Data are presented as the means \pm standard error of the mean (SEM). ${ }^{*} \mathrm{P}<0.05$ compared to the control group; ${ }^{*} \mathrm{P}<0.05$ compared to the MPTP/P-injected group. P-values were obtained by Duncan's tests.

that treatment with berberine improved the MPTP/P-induced decrease in motor balance and coordination $(\mathrm{P}<0.05)$.

Effects of berberine on short-term memory and neurogenesis in the dentate gyrus. The photomicrographs of BrdU/NeuN-positive cells in the hippocampal dentate gyrus are presented in Fig. 2A-E. The number of $\mathrm{BrdU} / \mathrm{NeuN}$-positive cells was counted to determine the level of neurogenesis (Fig. 2F). This number was $95.86 \pm 7.66 \mathrm{~mm}^{2}$ in the control group, $142.80 \pm 8.19 \mathrm{~mm}^{2}$ in the MPTP/P-injected group, $135.76 \pm 3.55 \mathrm{~mm}^{2}$ in the MPTP/P-injected and $20 \mathrm{mg} / \mathrm{kg}$ berberine-treated group, $107.46 \pm 38.81 \mathrm{~mm}^{2}$ in the MPTP/P-injected and $50 \mathrm{mg} / \mathrm{kg}$ berberine-treated group, and $99.10 \pm 6.77 \mathrm{~mm}^{2}$ in the MPTP/P-injected and $80 \mathrm{mg} / \mathrm{kg}$ berberine-treated group. These results indicated that neurogenesis in the dentate gyrus was increased in the mice in the MPTP/P-injected group $(\mathrm{P}<0.05)$; however, treatment with berberine significantly inhibited this effect $(\mathrm{P}<0.05)$.

Latency time was measured to evaluate the short-term memory of the mice (Fig. 2G). It was $155.33 \pm 9.14 \mathrm{sec}$ in the control group, $41.10 \pm 18.46 \mathrm{sec}$ in the MPTP/P-injected group,
$56.00 \pm 16.03 \mathrm{sec}$ in the MPTP/P-injected and $20 \mathrm{mg} / \mathrm{kg}$ berberinetreated group, $105.20 \pm 16.29 \mathrm{sec}$ in the MPTP/P-injected and $50 \mathrm{mg} / \mathrm{kg}$ berberine-treated group, and 110.98 $\pm 18.07 \mathrm{sec}$ in the MPTP/P-injected and $80 \mathrm{mg} / \mathrm{kg}$ berberine-treated group. These results indicated that short-term memory was impaired in the MPTP/P-injected mice $(\mathrm{P}<0.05)$; however, treatment with berberine alleviated this phenotype $(\mathrm{P}<0.05)$.

Effects of berberine on cleaved caspase-3 expression and DNA fragmentation in the hippocampal dentate gyrus. The photomicrographs of cleaved caspase-3-positive and TUNEL-positive cells in the hippocampal dentate gyrus are presented in Fig. 3A-E. The number of cleaved caspase-3-positive cells in the hippocampal dentate gyrus was also counted (Fig. 3F). This number was $54.46 \pm 4.75 \mathrm{~mm}^{2}$ in the control group, $163.95 \pm 13.08 \mathrm{~mm}^{2}$ in the MPTP/P-injected group, $152.84 \pm 13.07 \mathrm{~mm}^{2}$ in the MPTP/P-injected and $20 \mathrm{mg} / \mathrm{kg}$ berberine-treated group, $123.46 \pm 3.51 \mathrm{~mm}^{2}$ in the MPTP/P-injected and $50 \mathrm{mg} / \mathrm{kg}$ berberine-treated group, and $111.59 \pm 5.04 \mathrm{~mm}^{2}$ in the MPTP/P-injected and $80 \mathrm{mg} / \mathrm{kg}$ berberine-treated group. These results revealed that the expres- 

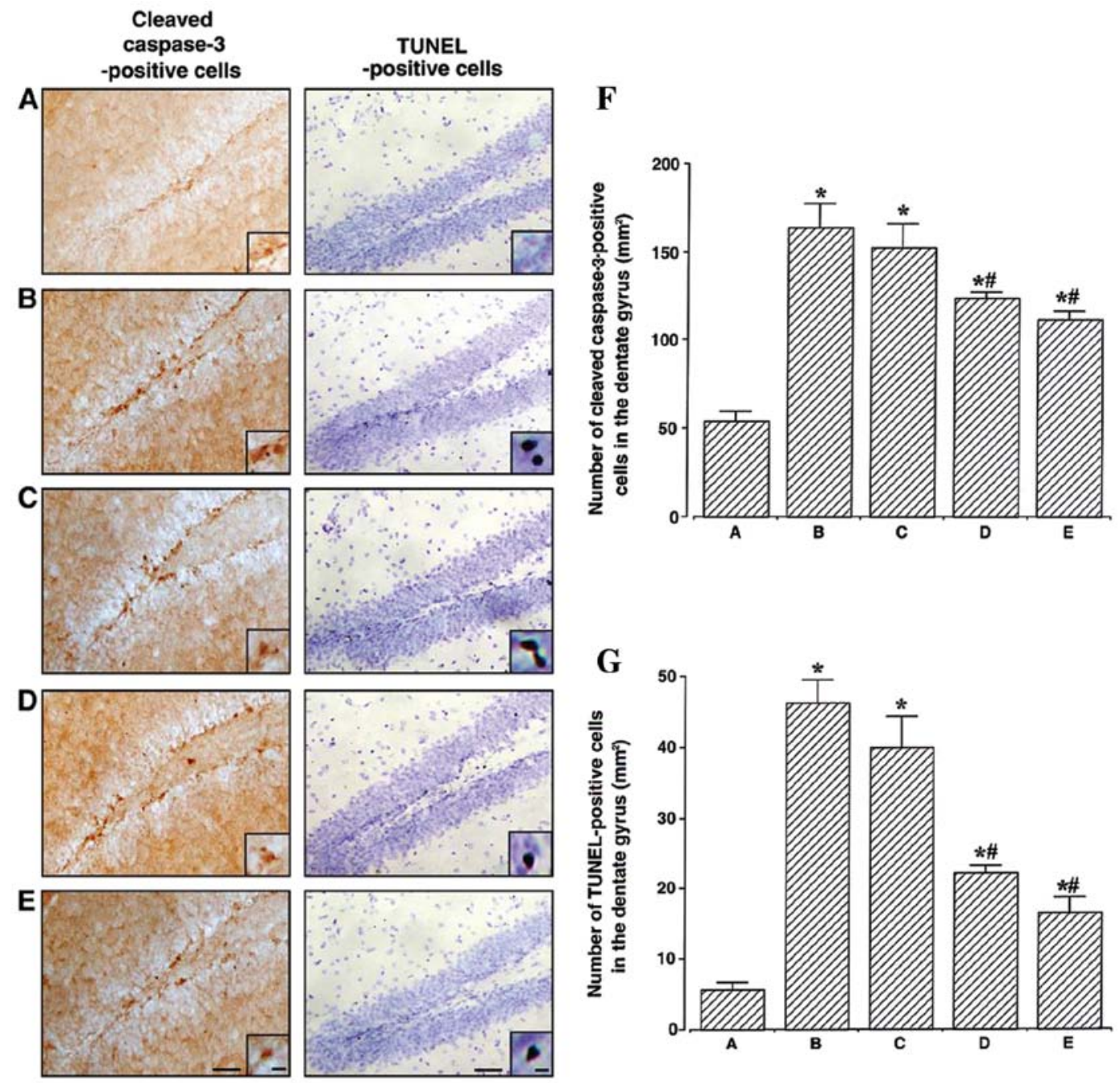

Figure 3. Effect of berberine on the numbers of cleaved caspase-3-positive and terminal deoxynucleotidyl transferase-mediated dUTP nick end-labeling (TUNEL)-positive cells in the hippocampal dentate gyrus. (A-E) Photomicrographs showing cleaved caspase-3-positive and TUNEL-positive cells in the hippocampal dentate gyrus, at low (scale bar, $200 \mu \mathrm{m}$ ) and high magnification (scale bar, $10 \mu \mathrm{m}$, enclosed images). (A) Control group,(B) 1-methyl-4-phenyl-1,2,3,6tetrahydropyridine/probenecid (MPTP/P)-injected group, (C) MPTP/P-injected and $20 \mathrm{mg} / \mathrm{kg}$ berberine-treated group, (D) MPTP/P-injected and $50 \mathrm{mg} / \mathrm{kg}$ berberine-treated group and (E) MPTP/P-injected and $80 \mathrm{mg} / \mathrm{kg}$ berberine-treated group. (F) Number of caspase-3-positive and (G) TUNEL-positive cells in the hippocampal dentate gyrus of mice from groups A-E. Data are presented as the means \pm standard error of the mean (SEM). ${ }^{*} \mathrm{P}<0.05$ compared to the control group; ${ }^{\text {P }}<0.05$ compared to the MPTP/P-injected group. P-values were obtained by Duncan's tests.

sion of cleaved caspase- 3 in the hippocampal dentate gyrus was enhanced in the MPTP/P-injected mice $(\mathrm{P}<0.05)$; however, treatment with berberine reduced its expression $(\mathrm{P}<0.05)$.

The number of TUNEL-positive cells in the hippocampal dentate gyrus (Fig. 3G) was determined as $5.72 \pm 1.00 \mathrm{~mm}^{2}$ in the control group, $46.33 \pm 3.21 \mathrm{~mm}^{2}$ in the MPTP/P-injected group, $39.92 \pm 4.44 \mathrm{~mm}^{2}$ in the MPTP/P-injected and $20 \mathrm{mg} / \mathrm{kg}$ berberine-treated group, $22.20 \pm 1.10 \mathrm{~mm}^{2}$ in the MPTP/P-injected and $50 \mathrm{mg} / \mathrm{kg}$ berberine-treated group, and $16.51 \pm 2.27 \mathrm{~mm}^{2}$ in the MPTP/P-injected and $80 \mathrm{mg} / \mathrm{kg}$ berberine-treated group. These results indicated that DNA fragmentation in the hippocampal dentate gyrus was enhanced in the MPTP/P-injected mice $(\mathrm{P}<0.05)$; however, treatment with berberine reduced DNA fragmentation $(\mathrm{P}<0.05)$.

Effect of berberine on Bax and Bcl-2 expression in the hippocampus. We determined the relative expression of $\mathrm{Bax}$ and $\mathrm{Bcl}-2$ proteins in the hippocampus by western blot analysis (Fig. 4).
When the level of Bax (24 kDa) was set to 1.00 in the control group, the level of Bax was $2.30 \pm 0.33$ in the MPTP/P-injected group, $2.10 \pm 0.26$ in the MPTP/P-injected and $20 \mathrm{mg} / \mathrm{kg}$ berberine-treated group, $1.46 \pm 0.19$ in the MPTP/P-injected and $50 \mathrm{mg} / \mathrm{kg}$ berberine-treated group and $1.53 \pm 0.23$ in the MPTP/P-injected and $80 \mathrm{mg} / \mathrm{kg}$ berberine-treated group. These results demonstrated that the injection of MPTP/P increased Bax expression in the hippocampus $(\mathrm{P}<0.05)$ and that treatment with berberine decreased Bax expression in the MPTP/P-injected mice $(\mathrm{P}<0.05)$.

When the level of Bcl-2 (26 kDa) was set to 1.00 in the control group, the level of $\mathrm{Bcl}-2$ was $0.43 \pm 0.08$ in the MPTP/P-injected group, $0.58 \pm 0.09$ in the MPTP/P-injected and $20 \mathrm{mg} / \mathrm{kg}$ berberine-treated group, $0.90 \pm 0.06$ in the MPTP/P-injected and $50 \mathrm{mg} / \mathrm{kg}$ berberine-treated group, and $0.91 \pm 0.07$ in the MPTP/P-injected and $80 \mathrm{mg} / \mathrm{kg}$ berberine-treated group. These results demonstrated that the injection of MPTP/P decreased Bcl-2 expression in the hippo- 


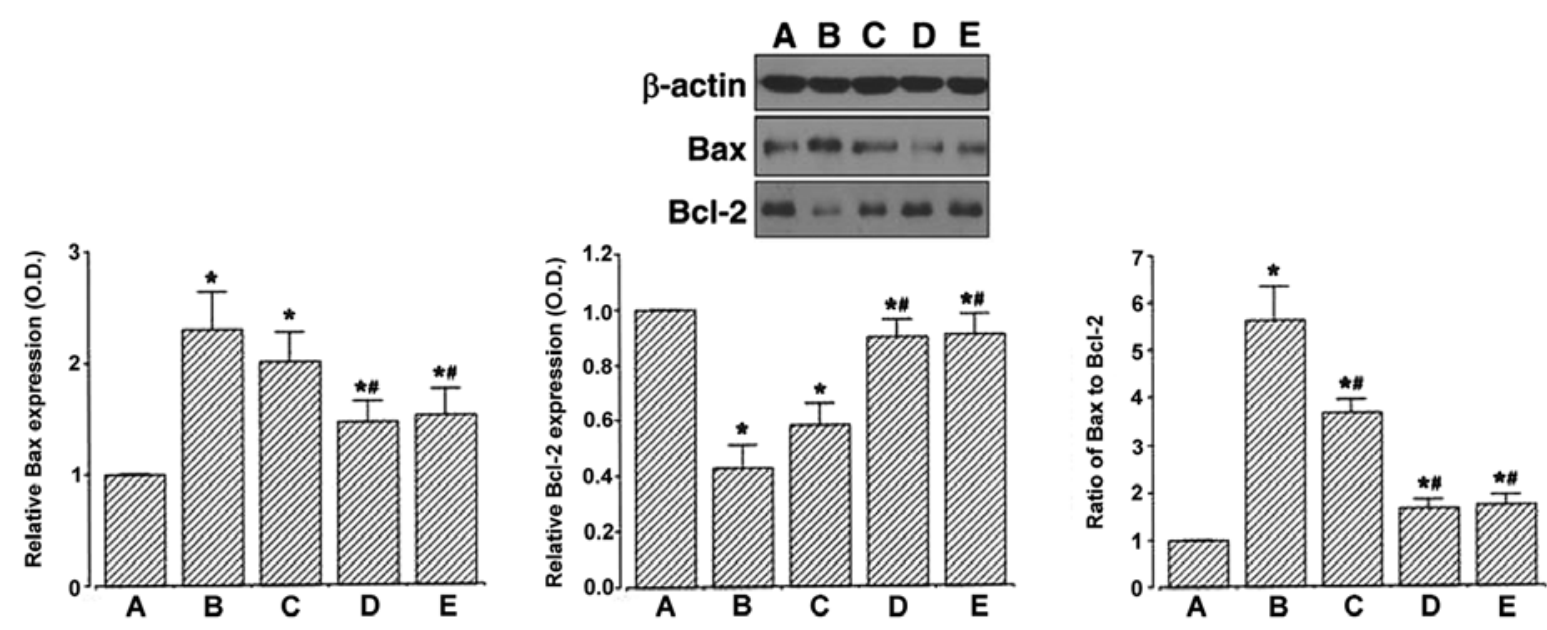

Figure 4. Effects of berberine on the expression of Bax and Bcl-2 in the hippocampus, as shown by western blot analysis, with $\beta$-actin as the loading control. (A) Control group, (B) 1-methyl-4-phenyl-1,2,3,6-tetrahydropyridine/probenecid (MPTP/P)-injected group,(C) MPTP/P-injected and $20 \mathrm{mg} / \mathrm{kg}$ berberine-treated group, (D) MPTP/P-injected and $50 \mathrm{mg} / \mathrm{kg}$ berberine-treated group and (E) MPTP/P-injected and $80 \mathrm{mg} / \mathrm{kg}$ berberine-treated group. The data are presented as the means \pm standard error of the mean (SEM). $\mathrm{P}<0.05$ compared to the control group; ${ }^{*} \mathrm{P}<0.05$ compared to the MPTP/P-injected group. P-values were obtained by Duncan's tests.

campus $(\mathrm{P}<0.05)$ and that treatment with berberine increased $\mathrm{Bcl}-2$ expression in the MPTP/P-injected mice $(\mathrm{P}<0.05)$.

The ratio of $\mathrm{Bax}$ to $\mathrm{Bcl}-2$ was then calculated. When the ratio of $\mathrm{Bax} / \mathrm{Bcl}-2$ in the control group was set to 1.00 , the ratio of $\mathrm{Bax} / \mathrm{Bcl}-2$ was $5.28 \pm 0.71$ in the MPTP/P-injected group, $3.68 \pm 0.27$ in the MPTP/P-injected and $20 \mathrm{mg} / \mathrm{kg}$ berberine-treated group, $1.64 \pm 0.19$ in the MPTP/P-injected and $50 \mathrm{mg} / \mathrm{kg}$ berberine-treated group, and $1.70 \pm 0.23$ in the MPTP/P-injected and $80 \mathrm{mg} / \mathrm{kg}$ berberine-treated group. These results demonstrated that the injection of MPTP/P increased the $\mathrm{Bax} / \mathrm{Bcl}-2$ ratio in the hippocampus $(\mathrm{P}<0.05)$ and that treatment with berberine decreased the ratio in the MPTP/P-injected mice $(\mathrm{P}<0.05)$.

\section{Discussion}

The selective degeneration of dopaminergic neurons and the reduced expression of TH in the SNpc, along with the decreased levels of dopamine transporter (DAT) and dopamine (DA) in the striatum are the main pathological hallmarks of PD (31). The decrease in dopamine synthesis and storage in the dopaminergic nerve endings has been shown to cause motor dysfunction in PD (32), while MPTP-induced TH reduction in the nigrostriatal pathway correlates with motor dysfunction (33). In a previous study, in MPTP/P-treated mice, latency in the rotarod test was decreased, and was accompanied by a decreased number of TH-positive cells in the SNpc and reduced TH-positive fiber density in the striatum (4). In our study, the MPTP/P injection decreased the number of TH-positive cells in the SNpc and reduced the density of TH-positive fibers in the striatum. MPTP/P treatment also reduced the latency in the beam walking test, indicating impaired motor balance and coordination skills. Treatment with berberine enhanced motor balance and coordination by preventing dopaminergic neuronal damage.

Memory impairment is an important symptom of patients with PD (34). MPTP-induced neuronal loss in the substantia nigra has previously been shown to result in altered working memory and impaired learning ability (35). In our study, shortterm memory in the step-down avoidance task was deteriorated in the mice with MPTP/P-induced PD, while treatment with berberine improved short-term memory. Berberine has been reported to improve spatial memory impairment in Alzheimer's disease (21), and prevent changes in oxidative stress and choline esterase activity, consequently alleviating memory impairment in diabetic rats (20).

The hippocampal dentate gyrus is a site of continuous production of new neurons in the adult hippocampus, and receives dopaminergic input from the neurons of the substantia nigra (2). Generally, the increase of neurogenesis in the hippocampal dentate gyrus improves learning ability and memory function $(8,9)$. However, the ablation of dopaminergic neurons is also known to induce neural stem/progenitor cell division (36). Increased neurogenesis in the hippocampal dentate gyrus is observed in various neurodegenerative diseases, including PD $(37,38)$. It is believed that increased neurogenesis following brain injuries is a compensatory mechanism to restore neuronal loss $(2,39)$. Park and Enikolopov (2) reported that the damage of dopaminergic neurons transiently induced hippocampal neurogenesis and they suggested that destruction of dopaminergic neurons in the substantia nigra may be the main cause of this induction. In our study, neurogenesis, which is a compensatory adaptive response to excessive apoptosis, was increased upon PD induction in the hippocampal dentate gyrus. Treatment with berberine alleviated the MPTP/ P-induced neurogenesis in the hippocampal dentate gyrus.

Apoptosis is an important event in neurodegenerative diseases, including PD $(4,40)$. A previous study reported that the number of TUNEL-positive and caspase-3 positive cells was increased in the hippocampal dentate gyrus of aged rats, indicating age-induced apoptosis (8). Increased numbers of TUNEL-positive and caspase-3-positive cells in the hippocampus are also associated with short-term memory impairment in rats with intracerebral hemorrhage, indicating intracerebral hemorrhage-induced apoptosis in the hippocampus (13). Decreased numbers of TUNEL-positive and caspase-3-positive 
cells indicate the inhibition of apoptosis $(9,13)$. The increased expression of Bcl-2 inhibits apoptosis, while the overexpression of Bax promotes it (41). Enhanced Bax expression with reduced Bcl-2 expression indicates intracerebral hemorrhage-induced enhancement of apoptosis in the hippocampus (13). In our experiments, the numbers of cleaved caspase-3-positive cells and TUNEL-positive cells in the hippocampal dentate gyrus were increased following MPTP/P injection, while treatment with berberine reduced these numbers in the mice with PD. Bcl-2 expression was decreased and Bax expression was increased, and as a result, the $\mathrm{Bax}$ to $\mathrm{Bcl}-2$ ratio was increased in the hippocampus following MPTP/P injection. Berberine treatment enhanced Bcl-2 expression and reduced Bax expression, and as a result, the Bax to $\mathrm{Bcl}-2$ ratio was decreased in the mice with PD. These results indicate that PD accelerates apoptotic neuronal death, but berberine treatment attenuates PD-induced apoptosis in the hippocampus. Berberine has also been shown to exert protective effects against apoptotic cell death in the hippocampus following ischemic brain injury $(23,42)$.

In this study, we demonstrate that berberine enhances motor balance and coordination by preventing dopaminergic neuronal loss in mice with PD. Berberine further ameliorated short-term memory impairment through the inhibition of apoptosis in the hippocampus. These effects of berberine were observed at doses exceeding $50 \mathrm{mg} / \mathrm{kg}$. Based on the present results, we suggest that berberine may serve as a therapeutic agent for the alleviation of memory impairment and motor dysfunction in patients with PD.

\section{References}

1. Dauer W and Przedborski S: Parkinson's disease: Mechanisms and models. Neuron 39: 889-909, 2003.

2. Park JH and Enikolopov G: Transient elevation of adult hippocampal neurogenesis after dopamine depletion. Exp Neurol 222: 267-276, 2010 .

3. Asanuma M, Miyazaki I and Ogawa N: Dopamine- or L-DOPA-induced neurotoxicity: the role of dopamine quinone formation and tyrosinase in a model of Parkinson's disease. Neurotox Res 5: 165-176, 2003.

4. Sung YH, Kim SC, Hong HP, Park CY, Shin MS, Kim CJ, Seo JH, Kim DY, Kim DJ and Cho HJ: Treadmill exercise ameliorates dopaminergic neuronal loss through suppressing microglial activation in Parkinson's disease mice. Life Sci 91: 1309-1316, 2012.

5. Yoon MC, Shin MS, Kim TS, Kim BK, Ko IG, Sung YH, Kim SE, Lee HH, Kim YP and Kim CJ: Treadmill exercise suppresses nigrostriatal dopaminergic neuronal loss in 6-hydroxydopamineinduced Parkinson's rats. Neurosci Lett 423: 12-17, 2007.

6. Eriksson PS, Perfilieva E, Bjork-Eriksson T, Alborn AM, Nordborg C, Peterson DA and Gage FH: Neurogenesis in the adult human hippocampus. Nat Med 4: 1313-1317, 1998.

7. Kempermann G, Jessberger S, Steiner B and Kronenberg G: Milestones of neuronal development in the adult hippocampus. Trends Neurosci 27: 447-452, 2004.

8. Kim SE, Ko IG, Kim BK, Shin MS, Cho S, Kim CJ, Kim SH, Baek SS, Lee EK and Jee YS: Treadmill exercise prevents aging-induced failure of memory through an increase in neurogenesis and suppression of apoptosis in rat hippocampus. Exp Gerontol 45: 357-365, 2010.

9. Shin MS, Ko IG, Kim SE, Kim BK, Kim TS, Lee SH, Hwang DS, Kim CJ, Park JK and Lim BV: Treadmill exercise ameliorates symptoms of methimazole-induced hypothyroidism through enhancing neurogenesis and suppressing apoptosis in the hippocampus of rat pups. Int J Dev Neurosci 31: 214-223, 2013.

10. Dash PK, Mach, SA and Moore AN: Enhanced neurogenesis in the rodent hippocampus following traumatic brain injury. J Neurosci Res 63: 313-319, 2001.

11. Felling RJ and Levison SW: Enhanced neurogenesis following stroke. J Neurosci Res 73: 277-283, 2003.
12. Ma L, Cui XL, Wang Y, Li XW, Yang F, Wei D and Jiang W: Aspirin attenuates spontaneous recurrent seizures and inhibits hippocampal neuronal loss, mossy fiber sprouting and aberrant neurogenesis following pilocarpine-induced status epilepticus in rats. Brain Res 21: 103-113, 2012.

13. Hwang L, Choi IY, Kim SE, Ko IG, Shin MS, Kim CJ, Kim SH, Jin JJ, Chung JY and Yi JW: Dexmedetomidine ameliorates intracerebral hemorrhage-induced memory impairment by inhibiting apoptosis and enhancing brain-derived neurotrophic factor expression in the rat hippocampus. In J Mol Med 31: 1047-1056, 2013.

14. Savitz SI and Rosenbaum DM: Apoptosis in neurological disease. Neurosurgery 42: 555-574, 1998.

15. Cohen GM: Caspases: the executioners of apoptosis. Biochem J 326: 1-16, 1997.

16. Oltvai ZN, Milliman CL and Korsmeyer SJ: Bcl-2 heterodimerizes in vivo with a conserved homolog, Bax, that accelerates programmed cell death. Cell 74: 609-619, 1993.

17. Wolf BB, Schuler M, Echeverri F and Green DR: Caspase-3 is the primary activator of apoptotic DNA fragmentation via DNA fragmentation factor-45/inhibitor of caspase-activated DNase inactivation. J Biol Chem 274: 30651-30656, 1999.

18. Imanshahidi $M$ and Hosseinzadeh $\mathrm{H}$ : Pharmacological and therapeutic effects of Berberis vulgaris and its active constituent, berberine. Phytother Res 22: 999-1012, 2008.

19. Kulkarni SK and Dhir A: On the mechanism of antidepressant-like action of berberine chloride. Eur J Pharmacol 589: 163-172, 2008.

20. Bhutada P, Mundhada Y, Bansod K, Tawari S, Patil S, Dixit P, Umathe S and Mundhada D: Protection of cholinergic and antioxidant system contributes to the effect of berberine ameliorating memory dysfunction in rat model of streptozotocin-induced diabetes. Behav Brain Res 220: 30-41, 2011.

21. Zhu F and Qian C: Berberine chloride can ameliorate the spatial memory impairment and increase the expression of interleuinlbeta and inducible nitric oxide synthase in the rat model of Alzheimer's disease. BMC Neurosci 7: 78, 2006.

22. Hung TM, Dang NH, Kim JC, Jang HS, Ryoo SW, Lee JH, Choi JS, Bae K and Min BS: Alkaloids from roots of Stephania rotunda and their cholinesterase inhibitory activity. Planta Med 76: 1762-1764, 2010.

23. Zhang Q, Qian Z, Pan L, Li H and Zhu H: Hypoxia-inducible factor 1 mediates the anti-apoptosis of berberine in neurons during hypoxia/ischemia. Acta Physiol Hung 99: 311-323, 2012.

24. Bae J, Lee D, Kim YK, Gil M, Lee JY and Lee KJ: Berberine protects 6-hydroxydopamine-induced human dopaminergic neuronal cell death through the induction of heme oxygenase-1. Mol Cells 35: 151-157, 2013.

25. Kwon IH, Choi HS, Shin KS, Lee BK, Lee CK, Hwang BY, Lim SC and Lee MK: Effects of berberine on 6-hydroxydopamine-induced neurotoxicity in PC12 cells and a rat model of Parkinson's disease. Neurosci Lett 486: 29-33, 2010.

26. Miyoshi E, Wietzikoski S, Camplessei M, Silveira R, Takahashi RN and Da Cunha C: Impaired learning in a spatial working memory version and in a cued version of the water maze in rats with MPTP-induced mesencephalic dopaminergic lesions. Brain Res Bull 58: 41-47, 2002.

27. Schneider JS, Tinker JP, VanVelson M and Giardiniere M: Effects of the partial glycine agonist D-cycloserine on cognitive functioning in chronic low dose MPTP-treated monkeys. Brain Res 860: 190-194, 2000.

28. Meredith GE, Totterdell S, Potashkin JA and Surmeier DJ: Modeling PD pathogenesis in mice: advantages of a chronic MPTP protocol. Parkinsonism Relat Disord 14 (Suppl 2): S112-S115, 2008

29. Lau YS, Trobough KL, Crampton JM and Wilson JA: Effects of probenecid on striatal dopamine depletion in acute and long-term 1-methyl-4-phenyl-1,2,3,6-tetrahydropyridine (MPTP)-treated mice. Gen Pharmacol 21: 181-187, 1990.

30. Meng XH, Liu P, Wang H, Zhao XF, Xu ZM, Chen GH and $\mathrm{Xu}$ DX: Gender-specific impairments on cognitive and behavioral development in mice exposed to fenvalerate during puberty. Toxicol Lett 203: 245-251, 2011.

31. Nutt JG, Carter JH and Sexton GJ: The dopamine transporter: importance in Parkinson's disease. Ann Neurol 55: 766-773, 2004.

32. Von Bohlen and Halbach O: Modeling neurodegenerative diseases in vivo review. Neurodegener Dis 2: 313-320, 2005. 
33. Schintu N, Frau L, Ibba M, Garau A, Carboni E and Carta AR Progressive dopaminergic degeneration in the chronic MPTPp mouse model of Parkinson's disease. Neurotox Res 16: 127-139, 2009.

34. Emre M: Dementia associated with Parkinson's disease. Lancet Neurol 2: 229-237, 2003.

35. Ho YJ, Ho SC, Pawlak CR and Yeh KY: Effects of D-cycloserine on MPTP-induced behavioral and neurological changes: potential for treatment of Parkinson's disease dementia. Behav Brain Res 219: 280-290, 2011.

36. Peng J, Xie L, Jin K, Greenberg DA and Andersen JK: Fibroblast growth factor 2 enhances striatal and nigral neurogenesis in the acute 1-methyl-4-phenyl-1,2,3,6-tetrahydropyridine model of Parkinson's disease. Neuroscience 153: 664-570, 2008.

37. Kim SE, Ko IG, Park CY, Shin MS, Kim CJ and Jee YS: Treadmill and wheel exercise alleviate lipopolysaccharide-induced short-term memory impairment by enhancing neuronal maturation in rats. Mol Med Rep 7: 31-36, 2013.
38. Lesemann A, Reinel C, Hühnchen P, Pilhatsch M, Hellweg R, Klaissle P, Winter C and Steiner B: MPTP-induced hippocampal effects on serotonin, dopamine, neurotrophins, adult neurogenesis and depression-like behavior are partially influenced by fluoxetine in adult mice. Brain Res 1457: 51-69, 2012.

39. Parent JM: Injury-induced neurogenesis in the adult mammalian brain. Neuroscientist 9: 261-272, 2003.

40. Liedhegner EA, Steller KM and Mieyal JJ: Levodopa activates apoptosis signaling kinase 1 (ASK1) and promotes apoptosis in a neuronal model: implications for the treatment of Parkinson's disease. Chem Res Toxicol 24: 1644-1652, 2011.

41. Elmore S: Apoptosis: a review of programmed cell death. Toxicol Pathol 35: 495-516, 2007.

42. Zhou XQ, Zeng XN, Kong H and Sun XL: Neuroprotective effects of berberine on stroke models in vitro and in vivo. Neurosci Lett 447: 31-36, 2008. 